\section{Cureus}

\title{
When a Drain is the Culprit: An Unexpected Case of Small Bowel Obstruction with Biliary Peritonitis
}

\author{
Maher Al Khaldi ${ }^{1}$, Félix Thibeault ${ }^{2}$, Richard Létourneau ${ }^{3}$ \\ 1. General Surgery, Centre Hospitalier de l'Université de Montréal (CHUM), Montreal, CAN 2. General \\ Surgery, Centre Hospitalier de l'Université de Montréal (CHUM), Montreal, CAN 3. Pancreatic and \\ Hepatobiliary Surgery, Centre Hospitalier de l’Université de Montréal (CHUM), Montreal, CAN
}

$\square$ Corresponding author: Maher Al Khaldi, alkmaher@gmail.com

Disclosures can be found in Additional Information at the end of the article

\section{Abstract}

Although postoperative abdominal drains are useful in therapeutic settings, their prophylactic role is debatable. We herein describe the case of a 30-year-old male who underwent bile duct resection with hepaticojejunostomy for cholangiocarcinoma. On postoperative day four, the patient developed biliary peritonitis. Explorative laparotomy revealed an obstruction of the afferent limb caused by an intestinal loop around a Jackson-Pratt (JP) drain. Removal of the drain resolved the obstruction which led to a significant improvement of the patient's clinical state. To the best of our knowledge, this is the second report of a bowel obstruction from a surgical drain. When placing abdominal drains, surgeons must take into consideration their indication as well as possible related complications, including intestinal obstruction.

Categories: General Surgery

Keywords: drains, bowel obstruction, cholangiocarcinoma, biliary peritonitis

\section{Introduction}

Prophylactic intra-abdominal drain placement following surgery aims at draining intraperitoneal collections and reducing the risk of subsequent infection [1]. However, the value of prophylactic drains has been debated for the past decades [2]. Growing evidence is showing no added benefit to prophylactic abdominal drainage, but drain placement may also increase patient morbidity [3]. Several complications include infection, bleeding, and tissue erosion. The following report describes a case of intestinal obstruction caused by a JacksonPratt (JP) drain, a very uncommon complication that is unknown to many practitioners.

Received 05/20/2019 Review began 05/21/2019 Review ended 06/08/2019 Published 06/21/2019

\section{(C) Copyright 2019}

Al Khaldi et al. This is an open access article distributed under the terms of the Creative Commons Attribution License CC-BY 3.0., which permits unrestricted use, distribution, and reproduction in any medium, provided the original author and source are credited.

\section{Case Presentation}

A 30-year-old male with no significant past medical or surgical history presented with cholestatic jaundice. An abdominal ultrasonography (USG) revealed an 11-mm obstructive lesion in the common bile duct with intrahepatic duct dilatation. An attempt at stent placement to relieve jaundice failed during endoscopic retrograde cholangiopancreatography (ERCP). A magnetic resonance cholangiopancreatography (MRCP) subsequently showed no gallstones but revealed a $7.0 \mathrm{~mm}$ segmental stenosis of the common hepatic duct with intrahepatic bile duct dilatation. The lesion was further characterized with an endoscopic ultrasonography (EUS), revealing a $19.0 \mathrm{~mm}$ lesion at the common hepatic duct, suspicious for a cholangiocarcinoma (Klatskin tumor). Thoracic, abdominal, and pelvic scans revealed no evidence of metastatic disease and no vascular involvement. The tumour was therefore deemed resectable. 


\section{Cureus}

The patient underwent an extended right hepatectomy, cholecystectomy, extrahepatic duct resection, and lymphadenectomy, followed by a Roux-en-Y hepaticojejunostomy (Figure 1).

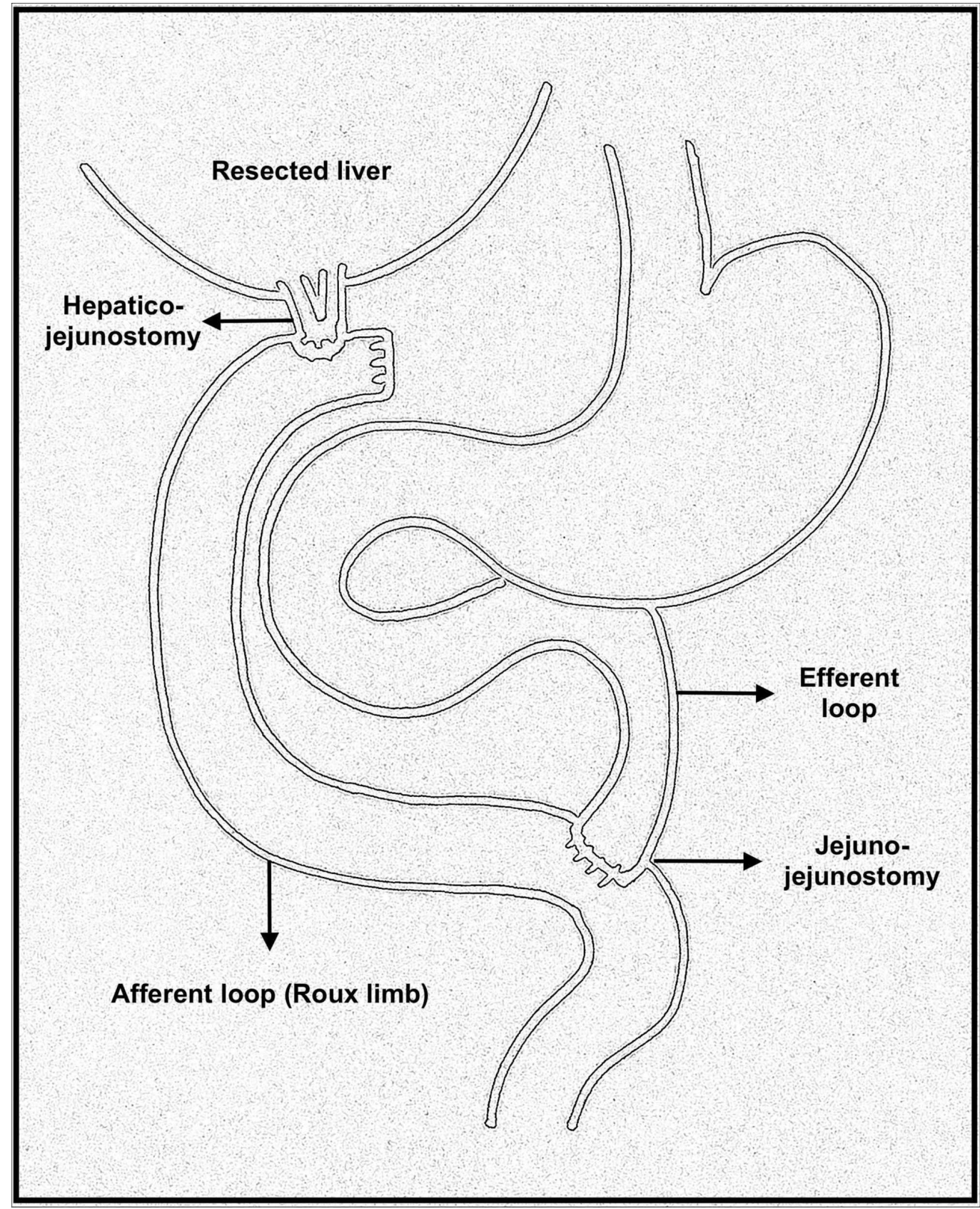

\section{FIGURE 1: A sketch depicting a Roux-en-Y hepatico- jejunostomy.}

Two prophylactic JP drains were placed at the right upper quadrant around the anastomoses to monitor for postoperative anastomotic leaks. The procedure was successfully performed and well tolerated by the patient without any immediate post-operative complications.

The pathology report later confirmed a perihilar extrahepatic bile duct adenocarcinoma. No evidence of lymph node involvement or metastatic disease was found. 


\section{Cureus}

On postoperative day four, the patient became febrile and complained of abdominal pain and vomiting. Physical examination revealed diffuse rebound tenderness was present, with maximal tenderness at the upper right quadrant. Bile was noted in both JP drains.

Elevated cholestatic markers were noted on laboratory results. An urgent abdominal CT scan revealed a severe dilation of the proximal jejunum (up to $5.2 \mathrm{~cm}$ ) with a possible transition point at the level of the proximal jejunum. A hypodense zone suggesting a perianastomotic collection of $5.0 \mathrm{~cm}$ x $3.0 \mathrm{~cm}$ was noted. The radiological images suggested an anastomotic leak secondary to the obstruction of the afferent intestinal loop, making biliary peritonitis the most likely diagnosis.

The patient underwent urgent exploratory laparotomy. A significant intestinal distention was noted upon opening of the abdomen. Surprisingly, the proximal jejunum was looped around one of the JP drains close to the hepaticojejunostomy (Figures 2-4).

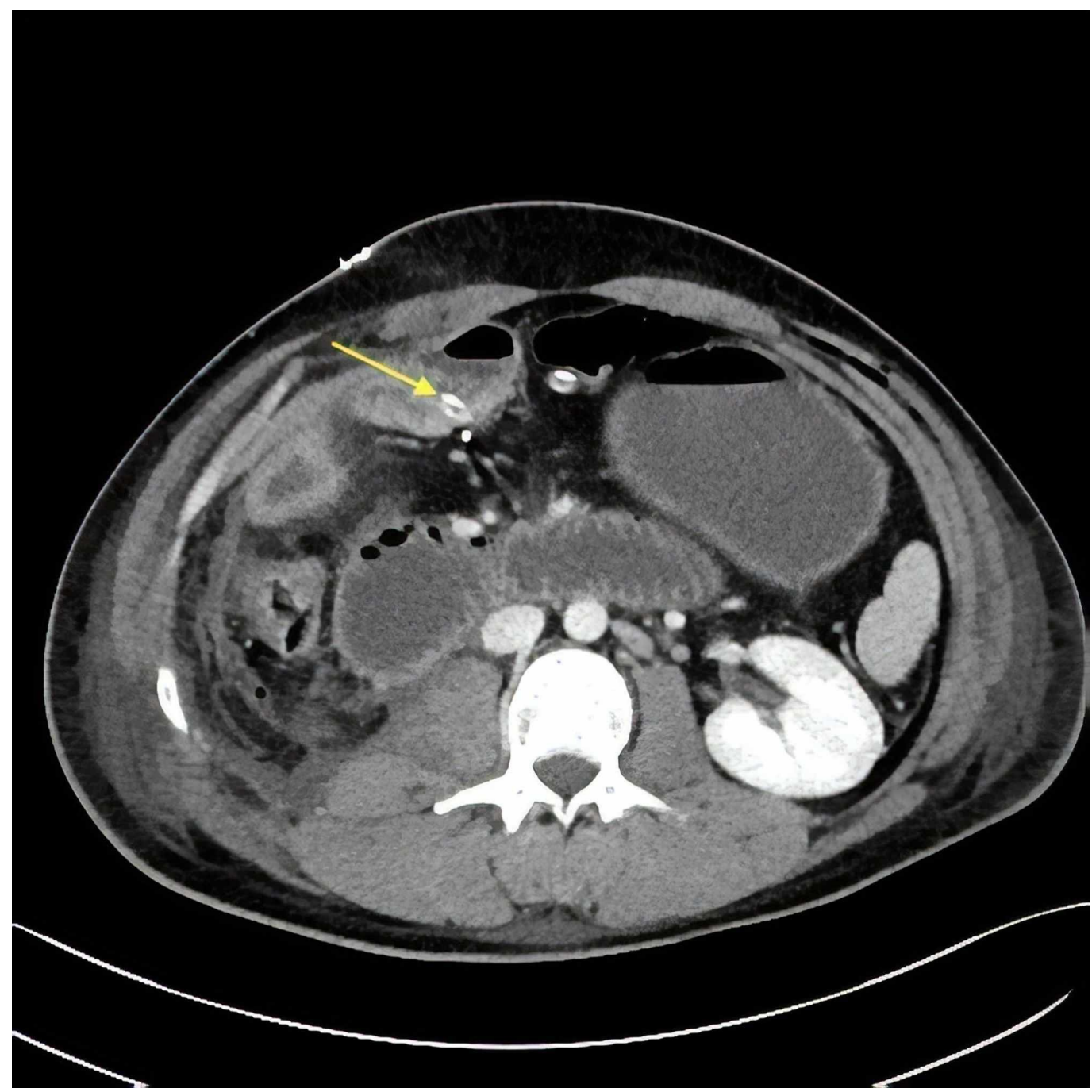

FIGURE 2: Axial view of the CT scan depicting the transition point of the obstruction close to the right abdominal JacksonPratt (JP) (arrow). 


\section{Cureus}

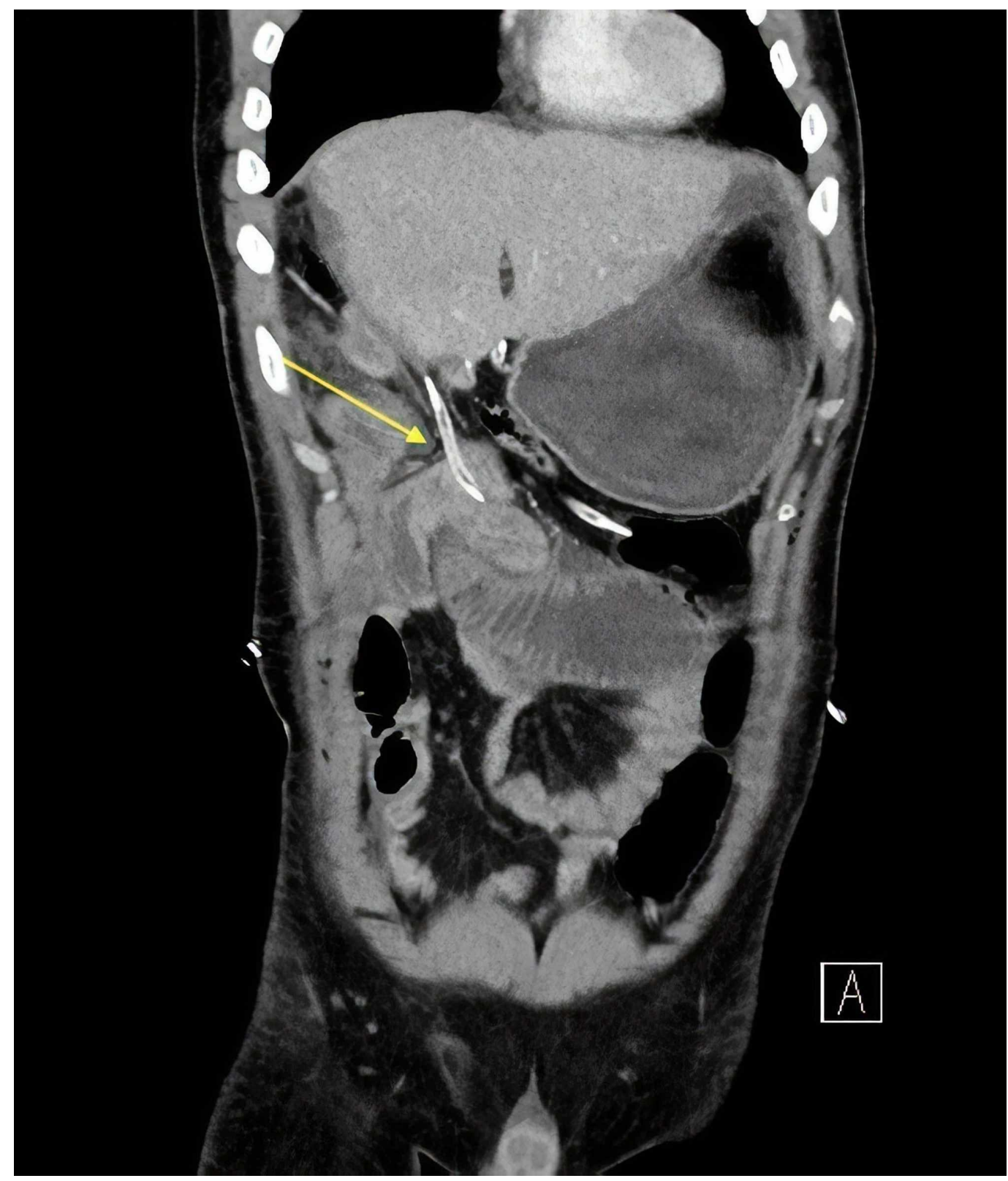

FIGURE 3: Coronal view of the CT scan showing the trajectory of the culprit drain. The stomach is distended as a result of the obstruction. 


\section{Cureus}

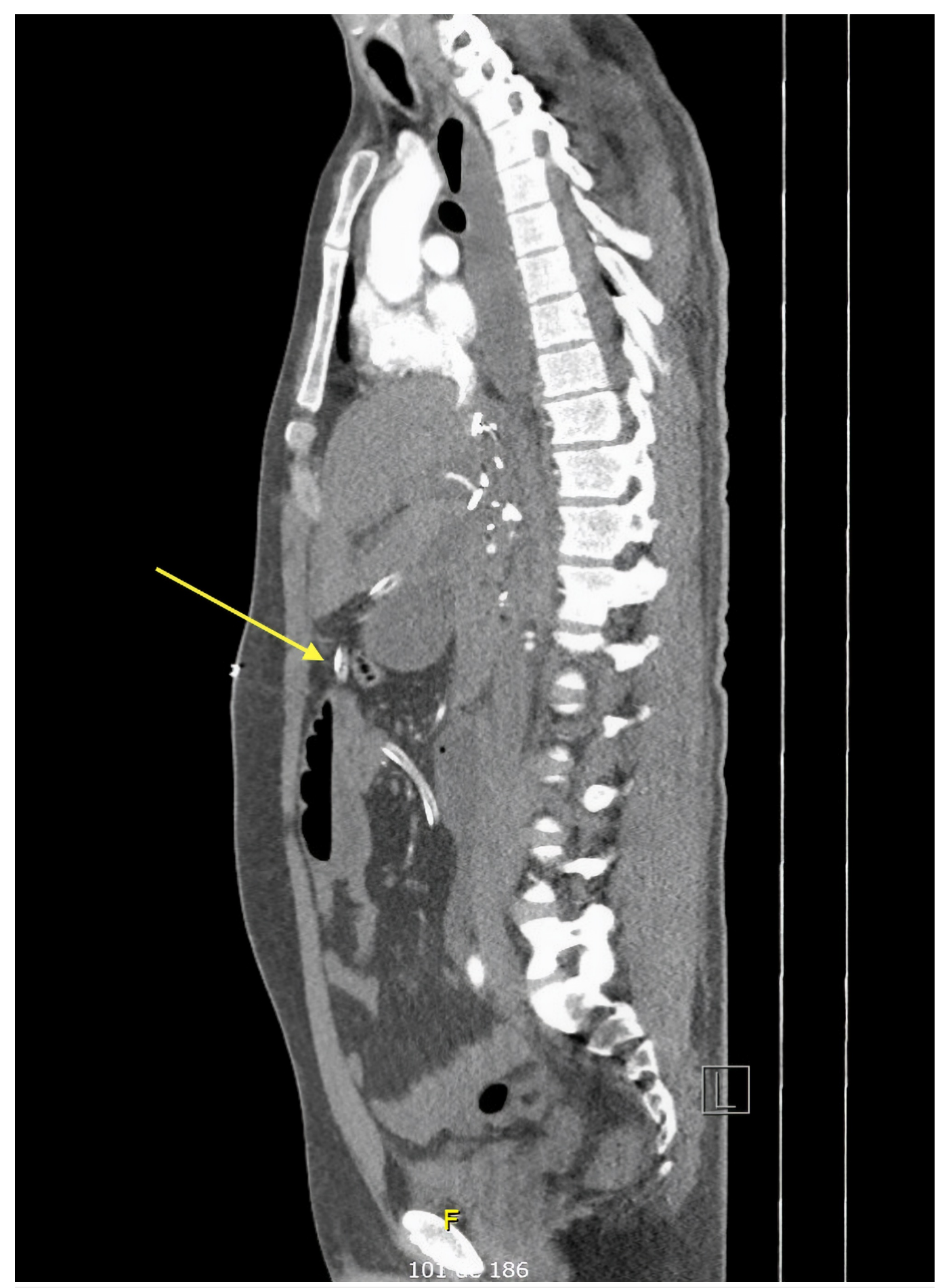

FIGURE 4: Sagittal view of the CT scan showing, once again, the drain's course throughout the abdomen.

Removal of the drain led to the spontaneous resolution of the obstruction and resulted in normal drainage of the intestinal content into the distal intestine.

The patient was hospitalized for several weeks due to multiple complications, including gastroparesis and transient hepatic insufficiency. After significant clinical improvement, the patient was discharged from the hospital with a closely scheduled follow-up appointment. 


\section{Discussion}

The use of surgical drains has been practiced for many years and was even described in the era of Hippocrates for drainage of empyema and ascites [4]. In the 19th century, the German surgeon Theodore Billroth supported prophylactic drainage after gastrointestinal surgery, claiming it led to better clinical outcome [5].

Prophylactic drains address intraperitoneal collections such as bile, blood, ascites and intestinal or pancreatic secretions. The accumulation of such biological liquids could lead to intraabdominal infection [1]. Bile and pancreatic secretions could also be toxic for surrounding tissue. In addition to eliminating dead space, drains allow early detection and quantification of intraabdominal hemorrhage and leakage of enteric suture lines [1]. Therefore, prophylactic drainage has gained popularity and acceptance throughout time as a simple, yet useful method to prevent complications after abdominal procedures.

However, despite its advantages, placement of a prophylactic drain remains debated in many instances. While it does not offer clinically significant benefits for most abdominal surgical procedures (especially colorectal anastomoses) [1, 3-4, 6], its use remains controversial and individualized in other interventions, especially in instances involving the upper abdomen (pancreatic, biliary, and gastric procedures) where there remains a further demand for welldesigned studies to clarify the value of prophylactic drainage [1].

Additionally, abdominal drains could be associated with complications, including hemorrhage, bacterial infection, hernia formation, foreign body reactions, and postoperative pain [1, 7-8]. Other less common, yet important, complications include the development of bronchoperitoneal fistula [9], bowel perforation from pressure necrosis [10], and small bowel evisceration [8].

Bowel obstruction is another very rare complication from intraabdominal drains. Shah et al. reported a case of a 78-year old male whose small bowel was twisted around a JP drain after undergoing low anterior resection with loop ileostomy for rectal cancer [11]. The obstructive phenomenon was described as a "maypole" effect. The patient underwent small bowel resection with primary anastomosis due to secondary intestinal necrosis. Additionally, Poon and colleagues [12] described a case where an abdominal drain led to small bowel obstruction after laparoscopic colectomy in an 82-year-old patient requiring reintervention. Another case of drain-associated intestinal obstruction after laparoscopic gastric bypass was reported by Rogers et al. [13].

To the best of our knowledge, this is the fourth case report ever published in the literature on intestinal obstruction caused by a surgical drain and the first such case following a hepatopancreato-biliary procedure (Table 1). 


\section{Cureus}

\begin{tabular}{|c|c|c|c|c|}
\hline Author & Year & Initial Surgery & Findings & Treatment \\
\hline $\begin{array}{l}\text { Rogers } \\
{[13]}\end{array}$ & 2007 & $\begin{array}{l}\text { Laparoscopic Roux-en-Y gastric bypass for } \\
\text { morbid obesity }\end{array}$ & $\begin{array}{l}\text { Loop of bowel twisted around the } \\
\text { abdominal drainage catheter }\end{array}$ & $\begin{array}{l}\text { Nonsurgical } \\
\text { removal of drain }\end{array}$ \\
\hline $\begin{array}{l}\text { Poon } \\
{[12]}\end{array}$ & 2009 & Laparoscopic anterior resection & $\begin{array}{l}\text { Herniation of the small bowel } \\
\text { mesentery into the side holes of } \\
\text { the silicon intra-abdominal drain } \\
\text { leading to mechanical obstruction }\end{array}$ & $\begin{array}{l}\text { Emergency } \\
\text { laparoscopy with } \\
\text { hernia reduction } \\
\text { and drain removal }\end{array}$ \\
\hline $\begin{array}{l}\text { Shah } \\
{[11]}\end{array}$ & 2014 & $\begin{array}{l}\text { Low anterior resection with loop ileostomy } \\
\text { for rectal cancer }\end{array}$ & $\begin{array}{l}\text { Small bowel twisted around the } \\
\text { drain }\end{array}$ & $\begin{array}{l}\text { Small bowel } \\
\text { resection with } \\
\text { primary } \\
\text { anastomosis due to } \\
\text { intestinal necrosis }\end{array}$ \\
\hline $\begin{array}{l}\text { Present } \\
\text { case }\end{array}$ & 2019 & $\begin{array}{l}\text { Extended right hepatectomy, } \\
\text { cholecystectomy, extrahepatic duct resection } \\
\text { and lymphadenectomy, followed by a Roux- } \\
\text { en-Y hepaticojejunostomy for Klatskin } \\
\text { tumour }\end{array}$ & $\begin{array}{l}\text { Proximal jejunum looped around } \\
\text { the JP drain, close to the } \\
\text { hepaticojejunostomy }\end{array}$ & $\begin{array}{l}\text { Explorative } \\
\text { laparotomy with } \\
\text { removal of JP drain }\end{array}$ \\
\hline
\end{tabular}

\section{TABLE 1: Reported cases of bowel obstruction from abdominal drains.}

JP: Jackson-Pratt

On preoperative imaging, a close trajectory of the JP alongside the afferent loop was noted without clear evidence pointing out the drain as the cause of the intestinal obstruction. Indeed, the etiology of the obstruction on imaging was only noted retrospectively. This case serves as an example of how unlikely it is to suspect a drain as a cause of intestinal obstructions.

All initial interventions of the four cases (including the following report) on intestinal obstruction from an abdominal drain were elective procedures. Of the four published cases on intestinal obstruction from an abdominal drain, only one case resolved nonoperatively [13]. Indeed, most cases required reintervention due to nonspecific findings on CT scan and/or worrisome postoperative presentations. This further emphasizes the importance of placing drains only when indicated, as undergoing a reoperation from iatrogenic complications increases the risk of patient morbidities.

\section{Conclusions}

Although therapeutic drainage of intraabdominal collections is beneficial, the role of prophylactic drainage following abdominal interventions remains controversial. There is currently growing evidence that prophylactic drain placement is not beneficial after different surgical interventions. Placement of prophylactic drains must be individualized. When placing them, the surgeon must take into consideration the possible related complications, including hemorrhage, infection, and rarely intestinal obstruction. Finally, with advances in surgical technique, easy access to antibiotics, radiological imaging and drainage, indications for routine prophylactic drains should be re-evaluated. 


\section{Additional Information \\ Disclosures}

Human subjects: Consent was obtained by all participants in this study. Conflicts of interest: In compliance with the ICMJE uniform disclosure form, all authors declare the following:

Payment/services info: All authors have declared that no financial support was received from any organization for the submitted work. Financial relationships: All authors have declared that they have no financial relationships at present or within the previous three years with any organizations that might have an interest in the submitted work. Other relationships: All authors have declared that there are no other relationships or activities that could appear to have influenced the submitted work.

\section{References}

1. Petrowsky H, Demartines N, Rousson V, Clavien PA: Evidence-based value of prophylactic drainage in gastrointestinal surgery: a systematic review and meta-analyses. Ann Surg. 2004, 240:1074. 10.1097/01.sla.0000146149.17411.c5

2. Messager M, Sabbagh C, Denost Q, et al.: Is there still a need for prophylactic intra-abdominal drainage in elective major gastro-intestinal surgery?. J Visc Surg. 2015, 152:305-313. 10.1016/j.jviscsurg.2015.09.008

3. Gavriilidis P, Hidalgo E, de'Angelis N, Lodge P, Azoulay D: Re-appraisal of prophylactic drainage in uncomplicated liver resections: a systematic review and meta-analysis. HPB. 2017, 19:16-20. 10.1016/j.hpb.2016.07.010

4. Puleo FJ, Mishra N, Hall JF: Use of intra-abdominal drains. Clin Colon Rectal Surg. 2013, 26:174. 10.1055/s-0033-1351134

5. Memon MA, Memon MI, Donohue JH: Abdominal drains: a brief historical review . Irish Med J. 2001, 94:6.

6. Kumar M, Yang SB, Jaiswal VK, Shah JN, Shreshtha M, Gongal R: Is prophylactic placement of drains necessary after subtotal gastrectomy?. World J Gastroenterol. 2007, 13:3738. 10.3748/wjg.v13.i27.3738

7. Nora PF, Vanecko RM, Bransfield JJ: Prophylactic abdominal drains. Arch Surg. 1972, 105:173176. 10.1001/archsurg.1972.04180080027005

8. Loh A, Jones PA: Evisceration and other complications of abdominal drains. Postgrad Med J. 1991, 67:687-688. 10.1136/pgmj.67.789.687

9. Pesce C, Galvagno SM, Efron DT, Kieninger AA, Stevens K: Retained drains causing a bronchoperitoneal fistula: a case report. J Med Case Rep. 2011, 5:185. 10.1186/1752-1947-5185

10. Nomura T, Shirai Y, Okamoto H, Hatakeyama K: Bowel perforation caused by silicone drains: a report of two cases. Surg Today. 1998, 28:940-942. 10.1007/s005950050257

11. Maypole' small bowel obstruction from Jackson Pratt drain . (2014). Accessed: May 19 2019: https://www.sages.org/meetings/annual-meeting/abstracts-archive/maypole-small-bowelobstruction-from-jackson-pratt-dr....

12. Poon CM, Leong HT: Abdominal drain causing early small bowel obstruction after laparoscopic colectomy. J Soc Laparoendoscopic Surg. 2009, 13:625.

13. Rogers AM, Cherenfant J, Kipnis S, Haluck RS: Drain-associated intestinal obstruction after laparoscopic gastric bypass. Obesity Surg. 2007, 17:980-982. 10.1007/s11695-007-9154-7 